UDC 141 Deleuze G.: 821.161.1-31-09 Dostoevskij F. M. https://doi.org/10.18485/ms_zmss.2020.97.3

\author{
Ольга Волчек \\ Санкт-Петербург, независимый исследователь \\ ovoltchek@hotmail.fr
}

Olga Voltchek

St. Petersburg, independent researcher ovoltchek@hotmail.fr

\title{
МЕТАМОРФОЗЫ ИДИОТА Ф. М. ДОСТОЕВСКОГО \\ В ФИЛОСОФИИ ЖИЛЯ ДЕЛЕЗА И СОВРЕМЕННЫХ ФРАНЦУЗСКИХ КОМПАРАТИВНЫХ ИССЛЕДОВАНИЯХ ${ }^{1}$
}

\section{METAMORPHOSES OF DOSTOYEVSKY'S THE IDIOT IN THE PHILOSOPHY OF GILLES DELEUZE AND CONTEMPORARY FRENCH COMPARATIVE STUDIES}

В статье рассматривается оригинальная концепция Идиота, восходящая к роману Ф. М. Достоевского, которая была предложена французским философом Жилем Делёзом, в книге Что такое философия? (1991), написанной в соавторстве с психоаналитиком Феликсом Гваттари. Делёз возводит Идиота в ранг концептуального персонажа, каковой служит высшим заступником его мысли, истинным субъектом его философии. Анализ корпуса философских работ Делёза, включающий как опубликованные сочинения, так и устный архив, состоящий из выступлений, интервью и лекций, прочитанных в университете Венсенн-Сен-Дени в 1979-1987, позволяет проследить как кристаллизируется образ Идиота в ходе интеллектуального становления французского философа, а также связанная с ним проблема русского человека, как понимает ее мыслитель. Вместе с тем, в статье рассматриваются метаморфозы образа Идиота в ряде актуальных французских компаративных исследований.

Ключевые слова: Жиль Делёз, Ф. М. Достоевский, идиот, князь Мышкин, концептуальный персонаж.

The article dwells upon the original conception of the Idiot going back to Dostoyevsky's novel that was provided by the French philosopher Gilles Deleuze in his book What is philosophy (1991), written jointly with Felix Guattari. Deleuze raises the Idiot to the level of a conceptual personage who serves as the highest defender of his thought, the true subject of his philosophy. The analysis of Deleuze's philosophical

1 Работа выполнена в рамках реализации проекта «Междисциплинарная рецепция творчества Ф. М. Достоевского во Франции 1968-2018 годов: филология, философия, психоанализ», поддержанного РФФИ, № 18-012-90011. 
oeuvre, that includes published works as well as his oral archive, comprised of his speeches, interviews and lectures given at the Vincennes-Saint-Denis University from 1979 to 1987, allows us to trace the way that the Idiot's image crystallizes throughout the intellectual formation of the French philosopher, along with the related problem of the Russian man, as understood by the thinker. Furthermore, the article examines the metamorphoses of the Idiot's image in a number of contemporary French comparative studies.

Key words: Gilles Deleuze, Fyodor Dostoyevsky, idiot, Prince Myshkin, conceptual personage.

Идиот Ф. М. Достоевского - князь Мышкин - по праву считается самым загадочным персонажем в творчестве русского писателя. Разгадать тайну личности Мышкина, растолковать смысл этого амбивалентного персонажа, о котором спорят и по сей день, пытались многие литературоведы, философы, психоаналитики, писатели, предлагая порой весьма противоречивые интерпретации образа «положительно прекрасного человека». Мы же попытаемся обратиться к философским сочинениям Жиля Делёза, предложившего одну из самых оригинальных концепций Идиота Достоевского как концептуального персонажа.

Жиль Делёз (1925-1995), французский философ, представитель так называемой «французской теории», о главных работах которого Различие и повторение (1968) и Логика смысла (1969) его современник Мишель Фуко отозвался следующими словами: «Долго это произведение будет витать над нашими головами, <...>, но когда-нибудь, возможно, век будет делёзовским» (Foucault 1994: 76). Сегодня Делёз является одним из самых цитируемых философов, чей концептуальный аппарат находит применение в широком спектре гуманитарных исследований. Но возникает закономерный вопрос: что может быть общего у Достоевского, русского писателя-почвенника XIX столетия, и радикального левого французского философа XX века, среди концептов которого выделяются «детерриториализация» и номадизм? На наш взгляд речь может идти скорее о виртуальной встрече двух великих мыслителей, о своеобразной форме сотворчества, сотрудничества, соразмышления, поскольку Делёз воспринимал писателей, философов или художников, творчество которых ему случалось изучать, а среди них Кант и Рембо, Бергсон и Пруст, Бэкон и Фуко, в виде живых собеседников. Воспринимая литературу и искусство как способы мыслить в различных планах реализации способности критического суждения, Делёз предлагает одну из самых оригинальных концепций Идиота, изложив ее пунктирно в одной из своих последних книг, написанной в соавторстве с психоаналитиком Феликсом Гваттари (1930-1992) Что такое философия?2 (1991), где персонаж Достоевского предстает в виде концептуального персонажа.

2 По мнению Ф. Досса, биографа двух французских мыслителей и соавторов нескольких работ, Гваттари не принимал активного участия в концептуальной разработке этой книги и еще меньше участвовал в ее написании (Dosse 2007: 538 sq). 
Концептуальный персонаж по Делёзу и Гваттари - «это не представитель философа, скорее даже наоборот: философ предоставляет лишь телесную оболочку для своего главного концептуального персонажа и всех остальных, которые служат высшими заступниками, истинными субъектами его философии. Концептуальные персонажи - "гетеронимы" философа, а имя самого философа - просто псевдоним его персонажей. Я - больше не я, но способность мысли видеть себя самое и развиваться через план, который в нескольких местах проходит сквозь меня» (Делез, Гваттари 1998: 83-84). Таким образом, концептуальный персонаж это не литературный образ, а своеобразная предпосылка мышления, исходя из которой философ творит концепты и создает образ мысли.

Для Делёза искусство мысли заключается в том, чтобы найти простую формулу для выражения того, что считается сложным. Чтобы мысль актуализировалась, необходим какой-то внешний стимул, какое-то событие, чтобы она освободилась от себя самой. Но проснувшись, она должна завоевывать новое знание, поскольку настоящий мыслитель сталкивается с новыми проблемами и ему нужно доказать свою способность творить новые концепты и тем самым препятствовать глупости. Для Делёза задача философии - это не созерцание, ни рефлексия, ни коммуникация, а создание, изобретение, сотворение концептов. Готовых концептов не существует, их необходимо вырабатывать. Но каждый концепт отсылает к проблеме, она скрыта, если ее не обнаружить, все остается абстракцией. Философия ставит проблемы и создает концепты, которые на них отвечают. История философии - это не пересказ трудов и дней философов прошлого, а нахождение новых проблем, с которыми соотносятся концепты.

Эти положения Делёза, высказанные в серии интервью с Клэр Парне для французского телевидения, записанных между 1988-1989 годами, явились своего рода подведением итогов и одновременно устной лабораторией книги Что такое философия?. По мнению одного из главных комментаторов творчества французского философа Д. Лапужада, рассматривающего философию Делёза как своего рода энциклопедию аберрантных движений, мысль о том, что, «как только мы “забываем” о проблеме, перед нами остается лишь общее абстрактное решение» (Lapoujade 2014: 15), которую Делёз сформулировал в Различии и повторении, является одной из главных для определения его философии. Для Лапужада автор программной работы Логика смысла является мыслителем логики, а не разума, искателем смысла, а не значения, исследователем внешних симптомов, а не скрытых тайн, он использует сырье мысли другого, встраивая его в архитектуру своей логики, которая оказывается всякий раз новой и сложной, далекой от классических рациональных моделей. Для него разум возникает из неразумия. «В логике Делёза всегда есть что-то шизофреническое», утверждает Лапужад (Lapoujade 2014: 13), философия для него «заключается прежде всего в постановке и опреде- 
лении проблемы, а не в понятиях и концептах, которые от нее зависят или позволяют ее разрешить» (Lapoujade 2014: 15). Для Делёза философствовать - значит самому стать Идиотом. Начать с нуля. Нести свет чистой мысли, сопротивляться. Сопротивляться торжествующей глупости. «Создавая персонаж Идиота, Достоевский сопротивляется вульгарности и глупости окружающей жизни. Как Ницше», — заявляет философ в Азбуке Жиля Делёза (L'Abécédaire de Gilles Deleuze 2004).

Другой вопрос - зачем философу литература? Философ не интерпретирует, не комментирует, не подвергает критике литературу, он объясняется с ее помощью и тем самым усложняет, проблематизирует, литературу, выводя ее на новый уровень рефлексии. Литература занимает важное место в творчестве Делёза, она постоянно сопровождает его собственные философские труды, «выступая в роли заступника, ходатая, через которого философ проводит в жизнь свои концепты, встречающие сопротивление в плане собственно философии» (Делёз 2002: 228). Помимо книг, целиком посвященных таким писателям как Пруст, Кафка, Захер-Мазох, Делёз в своей последней книге Критика и клиника (1993) собрал серию эссе о творчестве значимых для него писателей: Беккета, Мелвилла, Уитмена, Жарри, Кэрролла, Вольфсона и др., где он подводит итоги своей литературной критики, вернее, критики под знаком «клиники», утверждая вслед за Прустом, что каждый писатель изобретает «в языке новый язык - язык своего рода иностранный. [...] Вытаскивает язык из привычной колеи, заставляет его бредить» (Делёз 2002: 6). Однако Достоевскому Делёз не посвятил отдельного труда, он очень мало говорит о нем на страницах своих сочинений, что, вероятно и объясняет отсутствие критических работ на этот предмет. Тем не менее, тема Идиота, тема критики образа человека в его «славянском» измерении представляет, на наш взгляд, определенный интерес для широкого круга исследователей в области философии, теории кино и особенно литературы, открывая новые горизонты рецепции творчества русского писателя в западноевропейском контексте.

В данном исследовании мы попытались обратиться к ряду философских сочинений Делёза, начиная с самых ранних работ, где появляются первые отсылки к Достоевскому, и проследить как в них, а также в нескольких циклах его лекций, прочитанных в университете Венсенн -

3 В противоположность существующими версиям русского перевода заглавия этой книги, мы полагаем, что более релевантным будет следующее название Азбука Жиля Делёза: речь идет о документальном фильме общей длительностью 7,5 часов, где представлена серия бесед Делёза с его бывшей ученицей, философом Клэр Парне. Фильм был снят Пьером-Андре Бутаном в 1988-1989 гг. для французского телевизионного канала «Arte». Делёз, никогда не выступавший на телевидении, согласился на эту запись с условием, что она выйдет в эфир только после его смерти. Фильм был показан 15 января 1995 г. с разрешения философа, который, страдая от мучительной болезни, сказал Бутану в конце 1994 г.: «В свете моего нынешнего состояния, можно считать, что я уже умер». 
Сен-Дени в 1979-1987 выступает и кристаллизуется образ Идиота Достоевского как концептуального персонажа, а также скрытая за ним проблема русского человека, как ее понимает французский философ. Вместе с тем мы рассмотрим ряд актуальных французских междисциплинарных компаративных исследований, где Идиот Достоевского представляется как центральная фигура в литературном и артистическом пантеоне XX века.

Итак, в философии Делёза важным концептуальным персонажем, заступником и посредником философа является Идиот. «Идиот - это частный мыслитель, противостоящий публичному профессору (схоласту): профессор все время ссылается на схоластические концепты (человек - разумное животное), частный же мыслитель формирует концепт из врожденных сил, которыми по праву обладает каждый сам по себе (я мыслю). Таков весьма странный тип персонажа - желающий мыслить самостоятельно, посредством «естественного света» (Делез, Гваттари 1998: 81) ${ }^{4}$. Следует заметить, что, выводя Идиота в виде концептуального персонажа, Делёз и Гваттари нигде не упоминают князя Мышкина. Они скорее соотносят его, с одной стороны, с опытом Декарта, выстраивавшим свою философию в пику схоластике, а с другой стороны, с опытом подпольного парадоксалиста, подпольного мыслителя, каковой выступает в виде другого, нового идиота, которому «совершенно не нужны очевидности, он никогда не «смирится», с тем, что $3+2=5$, он желает абсурда — это уже другой образ мысли» (Делез, Гваттари 1998: 82). Этот новый идиот, славянин, возникший в ином контексте, также христианском, но русском, он противопоставлен идиоту прежнему - простецу Николая Кузанского, предшественнику cogito, в том смысле, что именно он говорит «Я», именно он предвосхищает cogito. «Прежний идиот хотел самостоятельно разобраться, что поддается пониманию, а что нет, что погибло, а что спасено, новый же идиот хочет, чтобы ему вернули погибшее, не поддающееся пониманию, абсурдное» (Делез, Гваттари 1998: 82).

Оппозицию между двумя типами мысли, публичным профессором и частным мыслителем Делёз находит у Л. Шестова, о чем он сам свидетельствует в одной из лекций (31.05.1983) прочитанных в Университете Венсенн - Сен-Дени ${ }^{5}$ (Deleuze 2017: 80). Эту новую оппозицию Шестов намечает в книге Киркегард и экзистенциальная философия. Глас вопиющего в пустыне (1936), где философ проводит мысль, что «Достоевский, и Киргегард, первый, не давая себе в том отчета, второй совершенно

4 Перевод немного изменен.

5 Устный архив магнитофонных записей курсов лекций, которые Делёз читал в Университете Венсенн - Сен-Дени в 1979-1987 гг. существует в виде частично расшифрованных и изданных электронных ресурсов, а также был опубликованы в 2017 г. с разбивкой по тематическому принципу в 5-томном издании, подготовленном М. Хаacom. 
сознательно, видели свою жизненную задачу в борьбе и преодолении того строя идей, который гегелевская философия как итог развития европейской мысли воплотила в себе» (Шестов 1992: 15). Для Кьеркегора частный мыслитель - это библейский Иов, у которого можно найти такое, что и не снилось прославленному философу и знаменитому профессору, каковым для Кьеркегора был Гегель. «От всеми прославляемого, знаменитого мыслителя, от великого ученого он пошел, и не пошел, а бросился, как к своему единственному спасителю, к “частному мыслителю", к библейскому Иову» (Шестов 1992: 16). То же сделал и Достоевский, считает Шестов, утверждая, что у него и у Кьеркегора «не только идеи, но и метод разыскания истины совершенно одинаковы и в равной мере не похожи на то, что составляет содержание умозрительной философии» (Шестов 1992: 21).

Интерес к философии Шестова, очевидно, был связан у Делёза с работой над книгой Ниџше и философия (1962), где впервые упоминается имя Достоевского в контексте подлинной «Критики чистого разума», которую «Шестову нравилось видеть в “Записках из подполья” Достоевского» (Делёз 2003: 188). Проблему образа мысли, как начала философии, требующего устранения всех пресуппозиций, Делёз развивает в своем главном оригинальном труде Различие и повторение (1968), где вновь возникает оппозиция между «идиотом» Декарта и русским идиотом с отсылкой к Шестову и подпольному человеку, который «больше не узнает себя ни в субъективных допущениях естественного мышления, ни в объективных допущениях культуры своего времени и не располагает компасом, чтобы совершить круг. Он - несвоевременен, ни временной, ни вечный» (Делёз 1998 :165).

Далее тема Идиота Достоевского возникает в одной из лекций курса о Спинозе (02.12.1980), где Делёз поднимает тему идиота как человека имплицитных пресуппозиций, чей образ восходит к Возрождению, к Николаю Кузанскому, затем он перескакивает через декартово cogito и, эмигрировав в Россию, принимает новый вид, «меняет аллюр» под воздействием православия. Делёз замечает при этом, что помимо произведений Достоевского, идиот, сливаясь с образом дурака, является фундаментальной фигурой русской литературы. «Здесь также, некоторым образом, является персонаж Достоевского, которого он назвал Идиотом, он безусловно гораздо драматичнее идиота Декарта, его болезнь и так далее... Но он что-то от этого сохранил. Силу естественного разума, сведенного к себе самому. Настолько сведенного к себе самому, что этот разум болен. Но при этом он сохраняет проблески. Князь, идиот, ничего не знает. Но это человек имплицитных пресуппозиций. Он все понимает» (Deleuze 2017: 332-333).

В дальнейшем в 1983-1985 годах Делёз развивает тему Идиота, обращаясь к кинематографу. Она фигурирует в его рассуждениях о культурализме и находит выражение как в лекциях этого периода, равно как 
в 2-томном труде о кино Кино I. Образ-движение (1983) и Кино II. Образ-время (1985). В понимании Делёза, культурализм соотносится с той связью, что сохраняется между философским концептом и культурой его происхождения. Русская душа - противоположность душе американской. Различие выражается в отношении к ситуации. Американская душа - это традиционный образ-действие, т. е. нужны все данные ситуации, и американец начинает действовать. Русский человек устроен по-другому, так же, как и японец Куросава. Представьте себе таких людей, говорит Делёз, они, в отличие от американцев, являются метафизиками, поскольку данные определенной ситуации, для них - не главное, они ищут что-то более важное и более фундаментальное: «Но что может быть важнее, глубже, чем данные ситуации? Если искать ответ в духе Достоевского, то его можно в конце концов найти, и это будет более глубокий ответ, чем данные ситуации, есть данные некоего вопроса, которые ситуация скрывает, погребает в себе. Куросава так поступает в фильме “Семь самураев”. Речь о том, чтобы поставить вопрос: что должен делать самурай в наше время? Таков вопрос, находящийся за пределами данных ситуации. И в этом Куросава самый русский из всех японцев» (Deleuze 2017: 262).

Очевидно, что, противопоставляя американский образ мысли, отличающийся известным прагматизмом, русскому образу мысли, который, с точки зрения французского философа, характеризуется склонностью к метафизике, Делёз оперирует педагогическими, так сказать, оппозициями. Важно, однако, что персонаж Идиота в его мысли никоим образом не сводится к болезни: русский идиотизм, то есть стремление выйти за рамки конкретной ситуации, чтобы поставить отвлеченный, абстрактный вопрос, равнозначен самому действенному философизму: чтобы начать мыслить, нужно иметь способность поставить себя идиотом. В интервью 1983 г. по поводу выхода в свет первой книги о кино Кино-1. Образ движение Делёз объясняет появление многочисленных работ о кино тем, что оно содержит множество идей, а то, что он называет Идеей с большой буквы, это образы, которые стимулируют мышление, и их природа варьируется в зависимости от рода искусства и его техник. В качестве примера повторения образа мысли, созданного вербальными средствами в романе, в кинематографическом языке он приводит пример Куросавы и рассуждает о персонажах Достоевского, которые постоянно попадают в какие-то неотложные ситуации, требующие незамедлительной реакции: «И вдруг персонаж останавливается и казалось бы безрассудно теряет свое время: это потому, что он ощущает, что еще не нашел скрытой “проблемы”, еще более неотложной, чем сама ситуация. Это, как если бы кто-то, за кем-то гонится бешеная собака, резко останавливался, чтобы задаться вопросом: "Но ведь есть проблема, что за проблема?” Это то, что Достоевский называет Идеей. И мы обнаруживаем, что у Куросавы есть Идеи в этом же смысле» (Deleuze 2003: 195). 
Наконец, более предметно образ Идиота Достоевского как концептуального персонажа, а также скрытая за ним проблема русского человека, как ее понимает Делёз, кристаллизуется в его лекции, прочитанной во Французской национальной киношколе «La Femis» 17 марта 1987 года и опубликованной впоследствии под названием «Что такое акт творения?».

Свое выступление Делёз начинает с того, как важно иметь идею для того, чтобы акт творения совершился. Идеи необходимо рассматривать как некие потенциалы, которые уже ангажированы в тот или иной способ выражения, будь то философия, искусство или наука, и которые являются неотъемлемой частью самого этого способа выражения. Но творческий человек ничего не создает просто так, он не работает ради своего удовольствия. Он создает только то, что для него является совершенно необходимым. Есть идеи в кино, которые могут быть выражены только кинематографическим языком. Но есть и такие, которые могли бы иметь ценность и в других дисциплинах, могли бы быть прекрасно выраженными, например, в романе. Но в этом случае они изменят способ движения, сменят аллюр по выражению Делёза. Если кинематографист желает экранизировать (адаптировать) какой-нибудь роман, это значит, что у него уже есть идеи, которые созвучны идеям, выраженным в этом романе. Когда речь идет о великом романе, это иной раз может стать поистине грандиозной встречей. И в качестве одного из самых прекрасных случаев такой встречи Делёз приводит пример Куросавы, который, как известно, предложил кинематографическую версию «Идиота»:

«Почему он оказывается столь близок Шекспиру или Достоевскому? Почему нужен японец для того, чтобы оказаться столь близким Шекспиру или Достоевскому? Я предложу ответ, который, как я полагаю, также немного касается и философии. С персонажами Достоевского происходит очень часто забавная вещь, которая объясняется одной небольшой деталью. Обыкновенно они слишком возбуждены. Какой-нибудь персонаж выходит из дома, выходит на улицу и говорит: “Таня, женщина, которую я люблю, зовет меня на помощь. Я бегу, она умрет, если я не пойду”. Он спускается по лестнице и встречает друга или же видит раздавленную собаку, которая умирает, и забывает, напрочь забывает, что его ждет Таня. Он забывает. Он пускается в разговор, встречает другого товарища, идет к нему выпить чаю и вдруг снова говорит: “Меня ждет Таня, мне нужно идти”. Что все это значит? У Достоевского персонажи беспрестанно захвачены каким-то неотложными делами, и когда они захвачены этими неотложными делами, каковые являются вопросами жизни и смерти, они в то же время знают, что есть еще более неотложная проблема - и они не знают, какая именно. Это их и останавливает. Все происходит так, как если бы в случае самой крайней необходимости — "Горит, мне надо уходить" — они говорили себе: "Нет, есть нечто более неотложное. И я не двинусь с места, пока не буду знать, что именно”. Это - Идиот. Это формула Идиота: “Вы знаете, есть более глубокая проблема. Я не очень хорошо понимаю, что это за проблема. Но оставьте меня. Гори все синим пламенем... нужно найти 
эту более насущную проблему”. И это Куросава узнает не от Достоевского. Персонажи Куросавы все такие. Это и есть прекрасная встреча» (Deleuze 2003: 295-296).

Если, выражаясь словами Делёза, говорить о прекрасной встрече двух великих мыслителей, то есть о его собственной встрече с Достоевским, то необходимо подчеркнуть, что Делёзу был необходим персонаж Идиота, чтобы самому стать идиотом, то есть частным мыслителем, человеком имплицитных пресуппозиций. Эту мысль развивает в своей книге с провокативным названием Превратиться в идиота. Политика Делёза французский философ Ф. Манг, специалист по творчеству Делёза, утверждая, что тема «идиота» «повсеместно присутствует во всем творчестве Делёза даже если эксплицитно она находит выражение лишь в нескольких конкретных пассажах», и что в одной из своих лекций в Венсенне Делёз провозгласил, что «философствовать - значит превратиться в идиота» ${ }^{6}$ (Mengue 2013: 10).

С другой стороны, что, собственно, привнес Делёз в науку о Достоевском? Если попытаться мыслить в его логике, необходимо решить вопрос, какую идею в романе, то есть в словесном творчестве как средстве выражения образа мысли, хотел воплотить автор, создавая своего заступника, своего посредника, своего концептуального персонажа Идиота в одноименном романе. Является ли князь Мышкин телесной оболочкой Идеи? Казалось бы, мы знаем ответ на этот вопрос. Достоевский сам сказал, что хочет создать образ «положительно прекрасного человека». Но князь Мышкин, самый неоднозначный персонаж в его творчестве, не дает нам однозначного ответа на этот вопрос, он словно таит в себе более глубокую проблему, которую необходимо вскрыть.

Вместе с тем Делёз открыл новую область для исследования, детерриториализировал Идиота как эстетическую фигуру и концептуального персонажа, сделал его продуктивным диспозитивом для трансверсального и компаративного анализа и тем самым проблематизировал новые возможности включения персонажей Достоевского в современность. Речь идет о достаточно многочисленных междисциплинарных компаративных исследованиях начала XXI века, в которых архетипическая фигура Идиота, нашедшая воплощение в различных видах искусства, занимает центральное место в виде фигуры сопротивления.

Важным этапом в изучении истории идиотии в ее различных проявлениях стал международный коллоквиум «Фигуры идиота», организованный в марте 2003 г. компаративистами В. Морон и К. де Рибопьер в Национальной студии современных искусств Френуа, собравший представителей различных областей знаний: психиатров, психоаналитиков, историков литературы и медицины. В книге, изданной в 2004 г. по мате-

6 Учитывая идиоматический характер французского выражения «faire l'idiot», его можно было бы перевести как «валять дурака», «делать глупость», «идиотничать». 
риалам коллоквиума, обстоятельно прослеживается, начиная с античности, история понятия идиотии в ее позитивной коннотации (идиот, как частное лицо, несведущий человек в противоположность магистрату в Древней Греции) и негативной, латинской, скорее уничижительной (невежда, лишенный знания глупец, ничего не смыслящий). Отправной точкой для рефлексии авторов сборника становится XIX век, тот момент, когда термин «идиот» потерял всякое позитивное значение, связанное с оригинальностью и исключительностью, превратившись в медицинский термин. Но Достоевский, написав свой роман, пересмотрел взгляд своей эпохи на идиота: в романе нашли место образы, связанные с болезнью, гением и его репрезентациями. Произошел переворот: «девалоризированный и обреченный идиот как самое презренное создание стал воплощением сингулярности и оригинальности, двух характеристик, учреждающих фундаментальные ценности модерности в XX веке» (Les figures de l'idiot: rencontres du Fresnoy 2004: 13). Авангардные течения $\mathrm{XX}$ века восстанавливает идиотизм, а художники отождествляют себя с идиотами, речь больше не о том, чтобы «быть идиотом», но «превратиться в идиота». Проявляясь в многочисленных ликах, идиот становится принципом выживания, противоречивые движения которого колеблются между девалоризацией и ревалоризацией.

Необходимо также упомянуть многолетнее исследование французского искусствоведа и писателя Ж.-И. Жуанне Идиотия. Искусство, жизнь, политика - метод, посвященного идиотии как одной из стратегий современного искусства. Автор утверждает, что решающее искусство прошлого века и идиотизм едины, «что “модерный” и “идиот" являются синонимами» (Jouannais 2003: 11). Автор проявляет свой идиотизм, сочетая это понятие с современным искусством, причем модерность понимается в широком смысле, включая как «фумистов» (fumistes) и «НепоследовательныX» (Incohérents) XIX века, так и дадаистов начала следующего столетия, а также некоторых современных художников, таких как Арно Лабель-Рожу, Маурицио Кателлан или Мартин Киппенбергер. Фигура художника как идиота держится вне доксы, поэтому она колеблется между моделью Достоевского и флоберовским дуэтом Бувара и Пекюше. Альфред Жарри с его папашей Убю тоже недалеко. В этой книге можно также найти примеры, более конкретно связанные с историей искусства (С. Дали). В более раннем эссе «Художники без творения. I wood prefer not to»7, опубликованном в 1997 и переизданном в 2009 г., Жуанне утверждал, что Идиот Достоевского бесспорно вписывается в современную семью идиотов в этом «веке Мышкина» (Jouannais 2009: 121), кото-

7 «I wood prefer not to» (Я не предпочел бы) - знаменитая формула Бартлби из рассказа Г. Мелвилла «Писец Бартлби. Уолл-стритская повесть» (1843), которую Делёз анализирует в эссе «Бартлби или формула» из своей последней книги Критика и клиника (Делёз 2002: 49- 62), где ставит этого персонажа в один ряд с героями Достоевского, Кафки и Музиля. 
рый открывается в конце XIX столетия и еще не сказал своего последнего слова.

Универсальная идея «идиота» как зоны сопротивления вырисовывается в сопоставлении, анализе Мышкина, как некоей архетипической референтной фигуры, с его метаморфозами, персонажами других писателей и кинематографистов в ряде компаративных исследований В. Дезульер, посвященных этой теме. Представляя Идиота Достоевского, совмещающего невинность младенца и мудрость, как главного героя XX века, «века князя Мышкина», она предлагает некий срез «дара идиотии», который, находя выражение в различных фигурах идиота, от мистических текстов IV в. до современного романа и кинематографа, показывает до какой степени то или иное представление идиотии «фатальным образом сохраняет память о духовности, укорененной в психологии и ментальной географии пространства одновременно национального и... космического» (Deshoulières 2003: 12). Рассматривая князя Мышкина среди прочих персонажей Ф. Мориака, Г. Грасса, И. Кальвино, С. Беккета, Т. Китано, У. Фолкнера, Х. Кортасара, В. Шаламова, А. Тарковского, В. Ерофеева и Л. Фон Триера исследовательница задается вопросом: какова социальная функция идиота в XX веке. В следующей работе Метаморфозы идиота, рассуждая в той же логике, она подчеркивает тот факт, что «идиот - это фигура весьма востребованная в художественном творчестве после Второй мировой войны и она воплощает собой фигуру критики знания, знания, которое не могло остановить катастрофу и даже оказалось ее соучастником» (Deshoulière 2005: 19). По мысли Дезульер эта идиотия имеет также критическое значение в отношении западной культуры в контексте истории XX века.

Все эти работы, объединенные так или иначе фигурой Идиота Достоевского, ставшим эмблематичным персонажем в век, именуемым то «веком Мышкина», то «веком делёзовским», свидетельствуют о том, что русский писатель выступает скорее как новатор, нежели архаист, скорее модернист, нежели консерватор. Речь идет, разумеется, не о политических взглядах писателя, но о создателе новых литературных форм, в том числе, новых персонажей. Именно новаторство Достоевскогописателя, родившего или возродившего к жизни таких персонажей, как идиот, подпольный человек или двойник, ставит его в один ряд с истинными мастерами мировой литературы, которые, вместе с тем, являются выразителями чаяний нации - таков Данте, Шекспир, Гёте, Пруст. Речь не о литературном национализме, но о сознании призвания не вторить традиции, но находить и выражать проблемы своего времени и своего народа. Достоевский, разумеется, не философ, но то, что новейшая философия, в частности, в лице и трудах Жиля Делёза, находит в его творчестве материал для концептуальных построений, свидетельствует о верности видения русским писателем тех стихий всечеловечности, что движут созданными им персонажами. 


\section{ЛИТЕРАТУРА}

Делез Жиль, Гваттари Феликс. Что такое философия/Перевод с франц. С. Л. Зенкина. СПб.: Алетейя, 1998а.

Делез Жиль. Различие и повторение / Перевод с франц. Н. Б. Маньковской и Э. П. Юровской. СПб.: Петерополис 19986.

Делёз Жиль. Критика и клиника/Пер. с франц. О. Е. Волчек и С. Л. Фокина/Послесл. и примеч. С. Л. Фокина. Спб.: Machina , 2002.

Делёз Жиль. Ницие и философия/Перевод О. Хомы под ред. Б. Скуратова. М.: Ад Маргинем, 2003.

Делёз Жиль. Переговоры. 1972-1990/Перевод с франц. В. Ю. Быстрова. СПб: Наука, 2004.

Шестов Лев. Киркегард и экзистенциальная философия (Глас вопиющего в пустыне). М.: Прогресс; Гнозис, 1992.

L'Abécédaire de Gilles Deleuze, de Pierre-André Boutang, entretiens avec Claire Parnet réalisés en 1988, Éditions Montparnasse, 2004.

Deleuze Gilles. Deux régimes de fous. Textes et entretiens 1975-1995. Ed. préparée par D. Lapoujade. Paris: Éd. de Minuit, 2003.

Deleuze Gilles. Le cours de Gilles Deleuze 1979-1987 [édité par Marc Haas]. T. I Notions, thèmes et concepts A-D. Canéjan : Editions Eidos, 2017.

Deshoulières Valérie. Le don d'idiotie entre éthique et secret depuis Dostö̈evski. La responsabilité silencieuse. Paris: L'Harmattan, 2003.

Deshoulière Valérie. Métamorphoses de l'idiot. Paris: Klincksieck, 2005.

Dosse François. Gilles Deleuze et Félix Guattari. Biographie croisée. Paris: La Découverte, 2007.

Foucault Michel. Dits et écrits. T. II: 1970-1975. Paris: Gallimard, 1994.

Jouannais J.-Y. L'Idiotie. Art. vie. politique - méthode. Paris: Beaux-arts Magazine livres, 2003.

Jouannais J.-Y. Artistes sans æeuvres. I wood prefer not to. Paris: Verticales, 2009.

Lapoujade David. Deleuze. Les mouvements aberrants. Paris: Éd. de Minuit, 2014.

Les figures de l'idiot: rencontres du Fresnoy. Mauron V. et Ribopierre C. de (dir). Paris: Léo Scheer, 2004.

Mengue Ph. Faire l'idiot. La politique de Deleuze. Meaux : Éd. Germina, 2013.

\section{LITERATURE}

Delez ZHil', Gvattari Feliks. Chto takoe filosofiia. Perevod s frants. S. L. Zenkina. SPb.: Aleteyya, 1998a.

Delez Zhil'. Razlichie i povtorenie. Perevod s frants. N. B. Man'kovskoi i E. P. Iurovskoi. SPb.: Peteropolis 1998b.

Delëz ZHil'. Kritika i klinika. Per. s frants. O. E. Volchek i S. L. Fokina. Poslesl. i primech. S. L. Fokina. Spb.: Machina, 2002.

Deleuze Gilles. Deux régimes de fous. Textes et entretiens 1975-1995. Ed. préparée par D. Lapoujade. Paris: Éd. de Minuit, 2003.

Delëz Zhil'. Nitsshe i filosofiia. Perevod O. Khomy pod red. B.Skuratova. M.:Ad Marginem, 2003.

Delëz Zhil'. Peregovory. 1972-1990. Perevod s frants. V. Iu. Bystrova. SPb: Nauka, 2004.

Deleuze Gilles. Le cours de Gilles Deleuze 1979-1987 [édité par Marc Haas]. T. I Notions, thèmes et concepts A-D. Canéjan : Editions Eidos, 2017.

Deshoulières Valérie. Le don d'idiotie entre éthique et secret depuis Dostoïevski. La responsabilité silencieuse. Paris: L'Harmattan, 2003.

Deshoulière Valérie. Métamorphoses de l'idiot. Paris: Klincksieck, 2005. 
Dosse François. Gilles Deleuze et Félix Guattari. Biographie croisée. Paris: La Découverte, 2007.

Foucault Michel. Dits et écrits. T. II: 1970-1975. Paris: Gallimard, 1994.

Jouannais J.-Y. L'Idiotie. Art. vie. politique - méthode. Paris: Beaux-arts Magazine livres, 2003.

Jouannais J.-Y. Artistes sans œuvres. I wood prefer not to. Paris: Verticales, 2009.

L'Abécédaire de Gilles Deleuze, de Pierre-André Boutang, entretiens avec Claire Parnet réalisés en 1988, Éditions Montparnasse, 2004.

Lapoujade David. Deleuze. Les mouvements aberrants. Paris: Éd. de Minuit, 2014.

Les figures de l'idiot: rencontres du Fresnoy. Mauron V. et Ribopierre C. de (dir). Paris: Léo Scheer, 2004.

Mengue Ph. Faire l'idiot. La politique de Deleuze. Meaux : Éd. Germina, 2013.

Shestov Lev. Kirkegard $i$ ekzistentsial'naia filosofiia (Glas vopiiushchego v pustyne). M.: Progress - Gnozis, 1992.

Олга Волчек

$$
\begin{gathered}
\text { МЕТАМОРФОЗЕ ИДИОТА Ф. М. ДОСТОЈЕВСКОГ } \\
\text { У ФИЛОСОФИЈИ ЖИЛА ДЕЛЕЗА И САВРЕМЕНИМ ФРАНЦУСКИМ } \\
\text { КОМПАРАТИСТИЧКИМ ИСТРАЖИВАЬИМА }
\end{gathered}
$$

\section{Резиме}

У раду се разматра оригинална концепција Идиота, која произилази из романа Ф. М. Достојевског, а коју је предложио француски философ Жил Делез у књизи Шӣa је философија? (1991), написаној у коауторству са психоаналитичарем Феликсом Гатаријем. Делез подиже Идиота на ранг концептуалног јунака, какав представља врховног заступника његове мисли, истинског субјекта његове философије. Анализа корпуса философских радова Делеза, која укључује како објављене списе, тако и усмени архив, сачињен од наступа, интервјуа и предавања одржаних на Универзитету Винсенс у Сент-Денизу (1979-1987), омогућава да се испрати кристализација лика Идиота током интелектуалног формирања француског философа, као и уско повезано с тим питање руског човека, како га поима мислилац. Поред тога, у чланку се разматрају метаморфозе лика Идиота у низу актуелних француских компаратистичких истраживања.

Кључне речи: Жил Делез, Достојевски, идиот, кнез Мишкин, концептуални јунак. 